\title{
A case of esophageal and endobronchial anthracosis
}

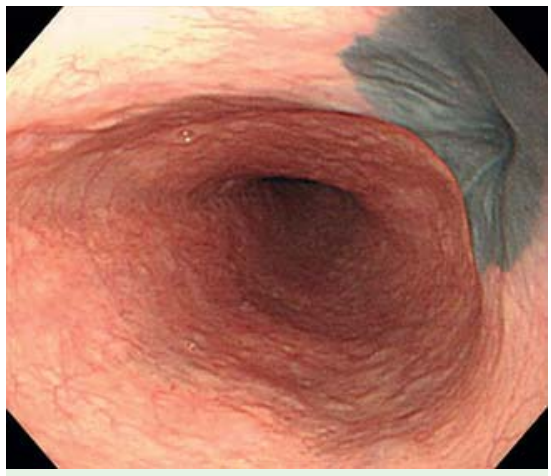

Fig. 1 Endoscopic findings: approximately $1-\mathrm{cm}$, round, black-pigmented flat lesion with a central depression, $30 \mathrm{~cm}$ from the incisors.

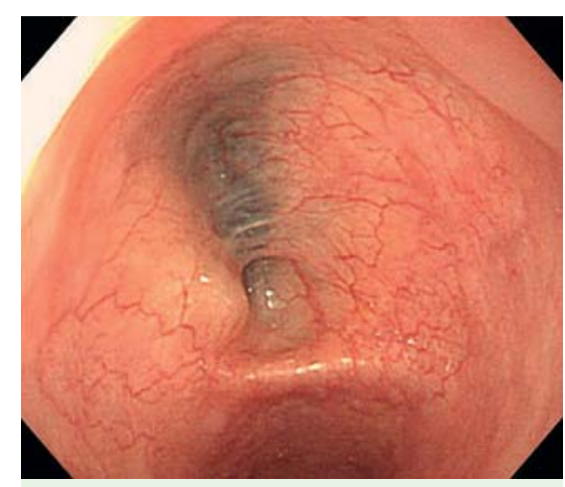

Fig. 2 Endoscopic findings: two diverticula with black pigment, $20 \mathrm{~cm}$ from the incisors.

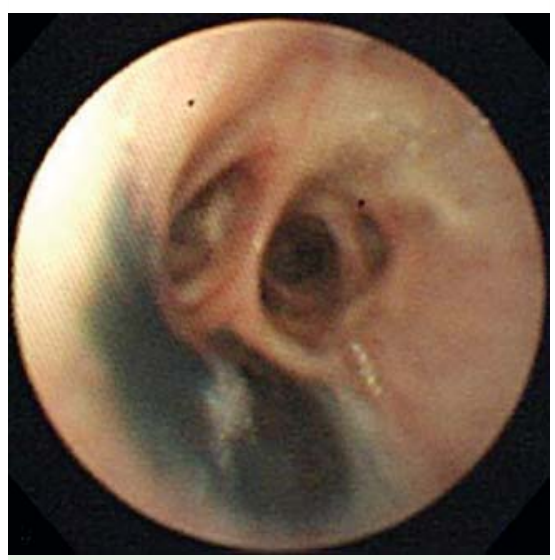

Fig. 4 Bronchoscopic view of anthracotic lesions in the main and intermedius bronchi of the right lung.

A 55-year-old woman underwent esophagogastroduodenoscopy as part of a general health examination and bronchoscopy for blood-tinged sputum noticed 3 days earlier. She had received treatment for pulmonary tuberculosis 20 years ago, and

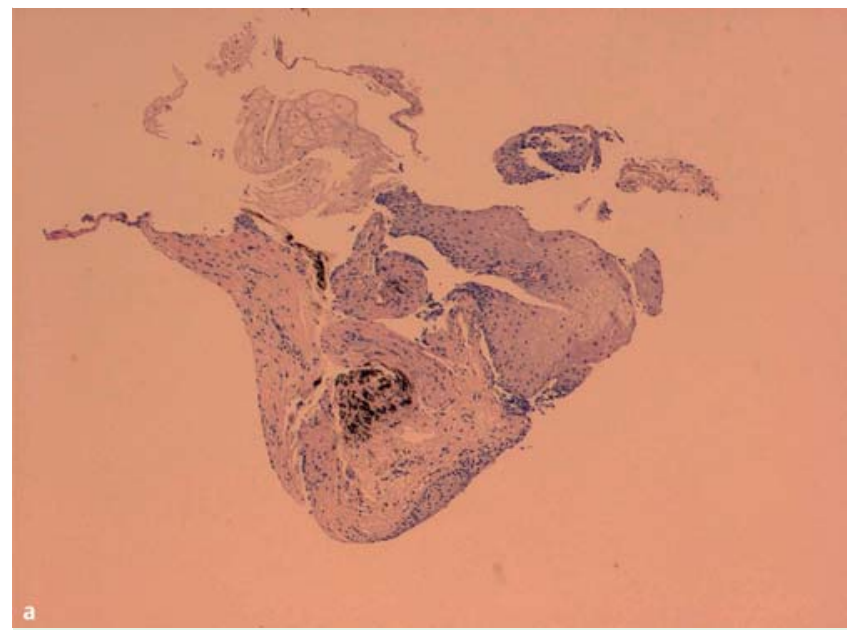

Fig. 3 Histological section showing atypical cells with black pigmentation beneath the mucosal epithelium (a: hematoxylin and eosin, magnification $\times 40$; b: hematoxylin and eosin, magnification $\times 200$ ).

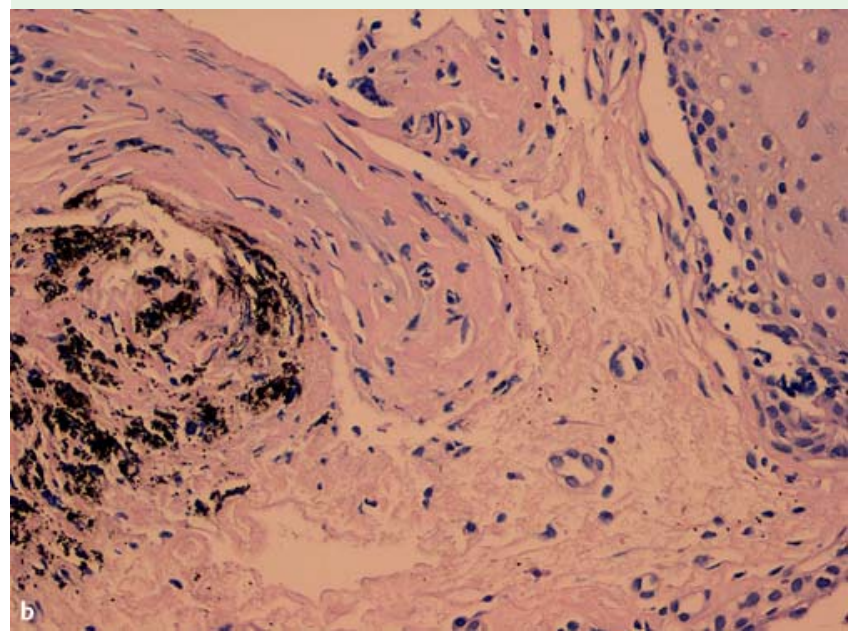

had been cured. She was a housewife with no history of smoking or occupational exposure to charcoal. A physical examination disclosed no abnormalities and laboratory values were within normal limits. Gastroesophageal endoscopy revealed an approximately $1-\mathrm{cm}$ round, black-pigmented flat lesion with a central depression, at $30 \mathrm{~cm}$ from the incisors ( $\mathbf{F i g . 1}$ ), and two diverticula with black pigmentation, at $20 \mathrm{~cm}$ from the incisors ( $\mathrm{Fig} .2$ ). As the lesions were very similar to malignant melanoma of the esophagus, a biopsy sample was obtained from the black flat lesion. Microscopic examination revealed atypical cells with black pigmentation underneath the mucosal epithelium (๑ Fig. 3).

The diagnosis of malignant melanoma was excluded. Bronchoscopic examination revealed anthracosis in the main and intermedius bronchi of the right lung ( $\bullet$ Fig. 4).
On the basis of the above-mentioned investigations, a diagnosis of esophageal anthracosis accompanied by endobronchial anthracosis was made.

Esophageal anthracosis is a rare disease [1 -4]. To our knowledge, there have been no reports of esophageal anthracosis occurring simultaneously with endobronchial anthracosis. Moreover, the mechanism of development of esophageal anthracosis is less well elucidated. There are two hypothesis: first, the traction diverticula and black-pigmented mucosal changes arise as a consequences of inflammation in the esophagus extending to the peribronchial lymph node, and second, the anthracotic pigment was deposited during a previous episode of an undiagnosed esophageal ulceration, followed by inadvertent ingestion of a coalcontaining substance $[1-3,5]$. The prognosis of esophageal anthracosis is uncer- 
tain and there are no reports on its treatment [4]. We think that the endoscopic findings are benign but histological confirmation is necessary to exclude the diagnosis of malignant melanoma of the esophagus $[2,6]$.

Endoscopy_UCTN_Code_CCL_1AB_2AC_3AH

J. K. Yang ${ }^{1}$, Y. S. Kim ${ }^{1}$, K. I. Kim', H. S. Koo' ${ }^{1}$, S. M. Kim ${ }^{1}$, T. H. Lee ${ }^{1}$, E. H. Im ${ }^{1}$, K. C. Huh ${ }^{1}$, Y. W. Choi ${ }^{1}$, Y. W. Kang ${ }^{1}$, S. J. Kwon ${ }^{2}$

1 Department of Gastroenterology, Konyang University College of Medicine, Daejeon, Korea

2 Department of Pulmonology, Konyang University College of Medicine, Daejeon, Korea

\section{References}

1 Vakharia BM, Pietruk T, Calzada R. Anthracosis of the esophagus. Gastrointest Endosc 1990; 36: 615-617

2 Murata T, Imai T, Hoshino Ket al. Esophageal anthracosis: lesion mimicking malignant melanoma. Pathol Int 2002; 52: 488-491

3 Park JH, Lee SH, Bae WY et al. Esophageal anthracosis with endobronchial tuberculosis: case report. Gastrointest Endosc 2006; 64: $1022-1024$

4 Lee JY, Kang SH, Chang JH et al. A case of esophageal anthracosis with polypoid features. Korean J Gastrointest Endosc 2009; 38: $20-23$

5 Ryu DS, Jung SM, Lee DH et al. CT and MR findings of bronchial anthracofibrosis. J Korean Radiol Soc 2000; 42: 481 - 486

6 Archer HA, Owen WJ. Primary malignant melanoma of the esophagus. Dis Esophagus 2000; 13 : $320-323$
Bibliography

Dol $10.1055 / \mathrm{s}-0029-1215417$

Endoscopy 2010; 42: E150 -E151

(c) Georg Thieme Verlag KG Stuttgart · New York . ISSN 0013-726X

\section{Corresponding author}

Y. S. Kim, MD

Department of Internal Medicine Konyang University College of Medicine 685 Gasuwon-dong Seo-gu

Daejeon 302-718

Korea

Fax: +82-42-6009090

stonedrag@hanmail.net 